\title{
Congenital Insensitivity to Pain with Multiple Fractures: A Case Report and Literature Review
}

\author{
Pan Zhou ${ }^{1}$, Chao Liu ${ }^{1}$, Jinpei Yang ${ }^{1}$, Shuai Zheng ${ }^{1}$, Xueshi Li $^{1}$, \\ Genlong Jiao ${ }^{1}$, Zhizhong $\mathrm{Li}^{1,2}$
}

\begin{abstract}
${ }^{1}$ Department of Orthopaedics, the First Affiliated Hospital of Jinan University, Jinan University, Guangzhou 510630, China

${ }^{2}$ The Fifth Affiliated Hospital of Jinan University, Jinan University, Heyuan 51700, Guangdong, China
\end{abstract}

\begin{abstract}
Congenital insensitivity to pain (CIP) is a rare autosomal recessive genetic disease, the main clinical manifestations are loss of pain or dullness, accompanied by a series of complications. We followed up a patient with CIP for 9 years, and a total of 4 fractures in 6 parts of the lower limbs were found. The patient presented with typical pain retardation, accompanied by osteomyelitis, multiple fractures, self-harm behavior (biting the tip of the tongue and fingers), and not being afraid of heat. A mutation was found on the sodium channel type IX a subunit (SCN9A) gene (chr2: 167056320 (EX27E), NM_002977. 3: c. 4796G>T (p. Arg1599Leu)). There is currently no effective treatment for this disease. We have adopted a combination of conservative and surgical treatment for this child's orthopedic disease (osteomyelitis and fracture). During the 4th fracture hospitalization, with the informed consent of the family, we used zoledronic acid to prevent fractures caused by low energy. Follow-up for 3 years found that zoledronic acid not only promoted fracture healing, but also avoided new fracture formation. Through reviewing the literature, we observe that this is the first report of using zoledronic acid to successfully avert new fractures in this type of patient. Now we summarize the treatment experience and review the literature in order to provide reference for the clinical treatment of this disease and enrich the SCN9A gene mutation spectrum.
\end{abstract}

Keywords: Congenital Insensitivity to Pain, Multiple Fractures, SCN9A, Zoledronic Acid

\begin{abstract}
Introduction
Congenital insensitivity to pain (CIP) is a disease in which the ability to feel physical pain is inhibited, with an incidence of 1: 25, 000. The condition was first reported by Dearborn in 1932 [1]. Children from birth do not feel the pain after the body injury, infant performance for little crying, oral or tongue ulcer recurrent attacks, and easy to be ignored by parents. It can be found in the orthopedics department due to recurrent fractures, Charcot's joints, heterotopic ossification, or osteomyelitis with age. In this case, we reported a CIP patient who had a total of 4 low-energy fractures during the 9-year follow-up. The diagnosis was finally confirmed by gene sequencing.
\end{abstract}

\section{Case report}

A 10-year-old boy (height $142 \mathrm{~cm}$, weight $33.6 \mathrm{~kg}$ ) mainly showed recurring fractures, painlessness after fractures, self-injurious behavior (biting tongue tip and fingernail) and not afraid of heat. No abnormalities in the rest of the senses and reflex (Fig 1). A mutation was found on the sodium channel type IX a subunit (SCN9A) gene (chr2: 167056320 (EX27E), NM_002977. 3: c. 4796G>T (p. Arg1599Leu)) (Fig 2m).

\begin{abstract}
The diagnosis and treatment process of this case was shown in Table 1. At 2 years and 11 months, he was admitted to the hospital for chronic osteomyelitis of the right femur for anti-infective treatment. The imaging examination revealed an old right tibial epiphyseal fracture (type IV) and was treated conservatively (Fig $\mathbf{2 a}, \mathbf{b})$.
\end{abstract}

At 5 years and 6 months, he was admitted to the hospital for "right tibial varus deformity; nonunion of right tibia epiphyseal fracture" and underwent right upper tibia epiphyseal bridge resection, bone grafting, epiphyseal lengthening, and external fixation (Fig 2c, d, k).

\begin{abstract}
At 5 years and 8 months, he was admitted to the hospital for "right femoral neck fracture" and underwent open reduction and plate screw internal fixation. At 1 year postoperative follow-up, the fracture end still did not achieve bone union. Physical examination showed that the length of the right lower limb was shortened by about $4 \mathrm{~cm}$ compared with the left side. Then, the nonunion of the right femoral neck was treated with scraping, bone grafting, and hollow nail internal fixation. After surgery, the right lower limb was fixed with braces and discharged.
\end{abstract}


The internal fixation device for the fracture of the right femoral neck was removed 1 year after surgery (Fig 2e-g).

At 7 years and 1 month, he was admitted to the hospital for "right distal femoral fracture" and underwent closed reduction and external fixation of the fracture. Postoperative antibiotics were used to prevent infection. On the 23rd day after the operation, the external fixation frame failed due to infection at the needle eye of the external fixation frame, and the right femoral supracondylar traction was used for treatment. Reexamination of X-ray at the 3rd week of skeletal traction revealed more callus formation at the fractured end, and external fixation was changed to plaster rest. After 4 months of follow-up, the fracture line was still obviously accompanied by local deformity. Open reduction, bone grafting, and kirschner wire internal fixation were performed (Fig 2h-k).

At 8 years and 1 month, he was admitted to the hospital for "left metatarsal fractures (the 1st, 2nd and 3rd metatarsal)". Imaging examination revealed an old compression fracture of the right heel bone, and open reduction of the first metatarsal fracture of the left foot was performed inside the kirschner wire fixation. After surgery, the left foot plaster cast was used for external fixation for 1.5 months, and $2.5 \mathrm{mg}$ zoledronic acid was injected intravenously. The fracture healed well on follow-up examination, and the Kirschner wire was removed. Half doses of zoledronic acid were injected again at 6 and 12 months. There were no complications and no new fractures during the 3-year follow-up (Fig 2l).

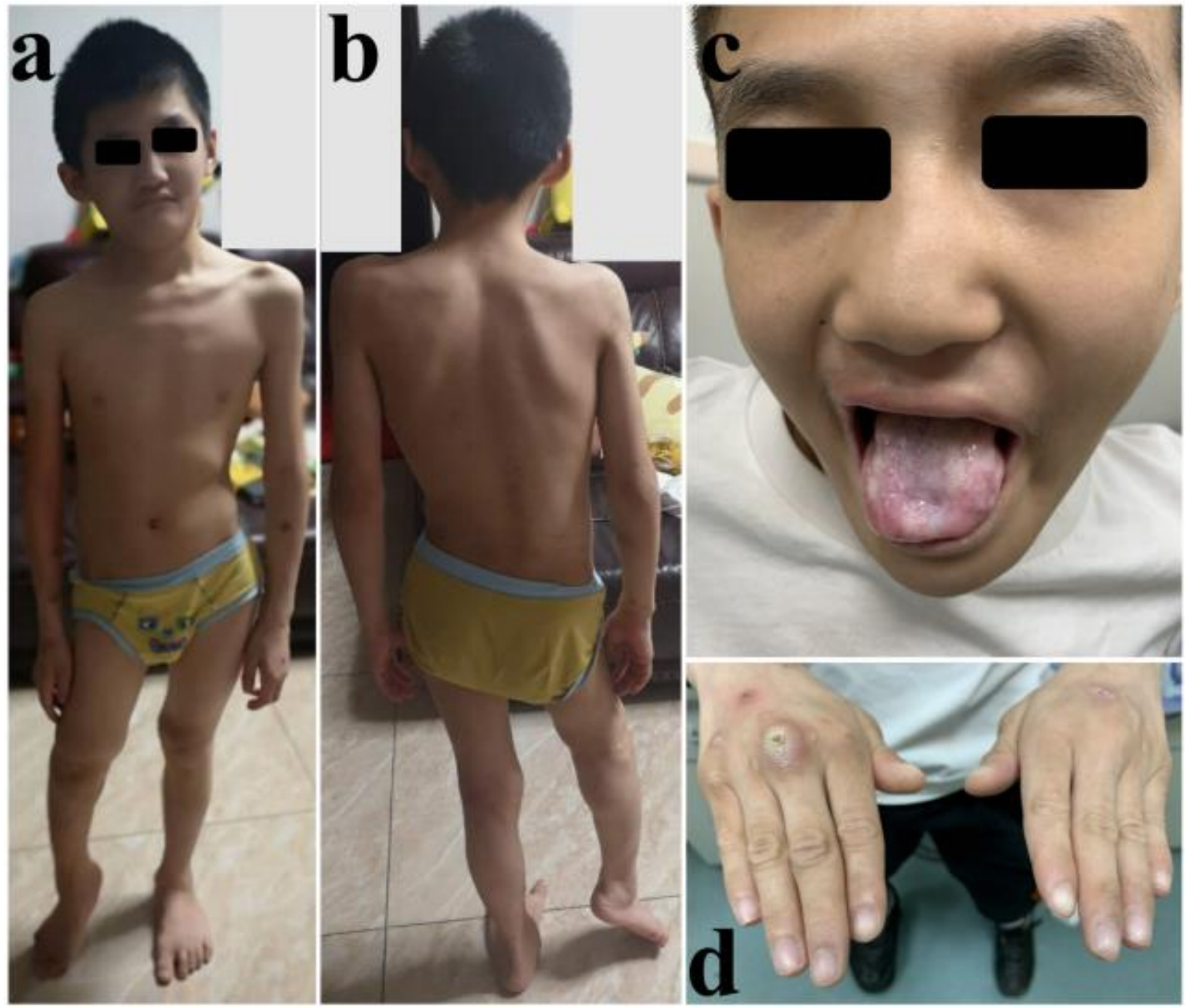

Fig 1 The appearance of the child at the age of 10. a Ventral view of standing position. b Dorsal image of standing position. $\mathbf{c}$ Images of tongue ulcers and tongue injuries. $\mathbf{d}$ Images of finger bite and dorsal injury of palm. 


\begin{tabular}{|c|c|c|c|c|}
\hline Age & Diagnosis & Cause & Performance and process & Treatment \\
\hline $\begin{array}{l}2 \text { years and } \\
11 \text { months }\end{array}$ & $\begin{array}{l}\text { Old right tibial epiphyseal } \\
\text { fracture (type IV); chronic } \\
\text { osteomyelitis of the right } \\
\text { femur }\end{array}$ & $\begin{array}{l}\text { To fall; a slight } \\
\text { violence }\end{array}$ & $\begin{array}{l}\text { Two months after the fall, an abnormal } \\
\text { posture of right lower limb was found } \\
\text { during walking, painless, and there was } \\
\text { an old fracture at the time of the visit }\end{array}$ & $\begin{array}{l}\text { Conservative treatment, } \\
\text { plaster external fixation }\end{array}$ \\
\hline $\begin{array}{l}5 \text { years and } \\
6 \text { months }\end{array}$ & $\begin{array}{l}\text { Right tibial varus deformity; } \\
\text { Nonunion of right tibia } \\
\text { epiphyseal fracture }\end{array}$ & $\begin{array}{l}\text { Clinical follow-up } \\
\text { was detected }\end{array}$ & $\begin{array}{l}\text { No obvious trauma, painless, the } \\
\text { right lower limb was } 4.2 \mathrm{~cm} \text { shorter } \\
\text { than the left, and varus of the right } \\
\text { knee is about } 25^{\circ}\end{array}$ & $\begin{array}{l}\text { Epiphyseal bridge resection, } \\
\text { bone grafting, epiphyseal } \\
\text { lengthening, and external } \\
\text { fixation. }\end{array}$ \\
\hline $\begin{array}{l}5 \text { years and } \\
8 \text { months }\end{array}$ & Right femoral neck & $\begin{array}{l}\text { To fall; a slight } \\
\text { violence }\end{array}$ & $\begin{array}{l}\text { Painless, deformity, restricted } \\
\text { movement, X - ray examination } \\
\text { showed a femoral neck fracture }\end{array}$ & $\begin{array}{l}\text { Open reduction and plate screw } \\
\text { internal fixation; } \\
\text { Bone nonunion: hollow nail } \\
\text { intemal fixation }\end{array}$ \\
\hline $\begin{array}{l}7 \text { years and } \\
1 \text { month }\end{array}$ & $\begin{array}{l}\text { Right distal femoral } \\
\text { fracture }\end{array}$ & $\begin{array}{l}\text { To fall; a slight } \\
\text { violence }\end{array}$ & $\begin{array}{l}\text { Painless, deformity, restricted } \\
\text { movement }\end{array}$ & $\begin{array}{l}\text { Closed reduction, external } \\
\text { fixed bracket; Infection: } \\
\text { supracondylar traction of femur } \\
\text { ( } 3 \text { weeks), plaster external } \\
\text { fixation; Bone nonunion: open } \\
\text { reduction, bone grafting, and } \\
\text { kirschner wire internal fixation }\end{array}$ \\
\hline $\begin{array}{l}8 \text { years and } \\
1 \text { month }\end{array}$ & $\begin{array}{l}\text { Left metatarsal fractures (the } \\
\text { 1st, } 2 \text { nd and 3rd metatarsal); } \\
\text { Old compression fracture of } \\
\text { the right heel bone }\end{array}$ & $\begin{array}{l}\text { Accidental discovery } \\
\text { in review }\end{array}$ & $\begin{array}{l}\text { No obvious trauma, painless, } \\
\text { unrestricted activities }\end{array}$ & $\begin{array}{l}\text { Open reduction, kirschner wire } \\
\text { internal fixation; Intravenous } \\
\text { infusion of zoledronic acid }\end{array}$ \\
\hline
\end{tabular}

Table 1 Summary of the 9-year follow-up diagnosis and treatment process.
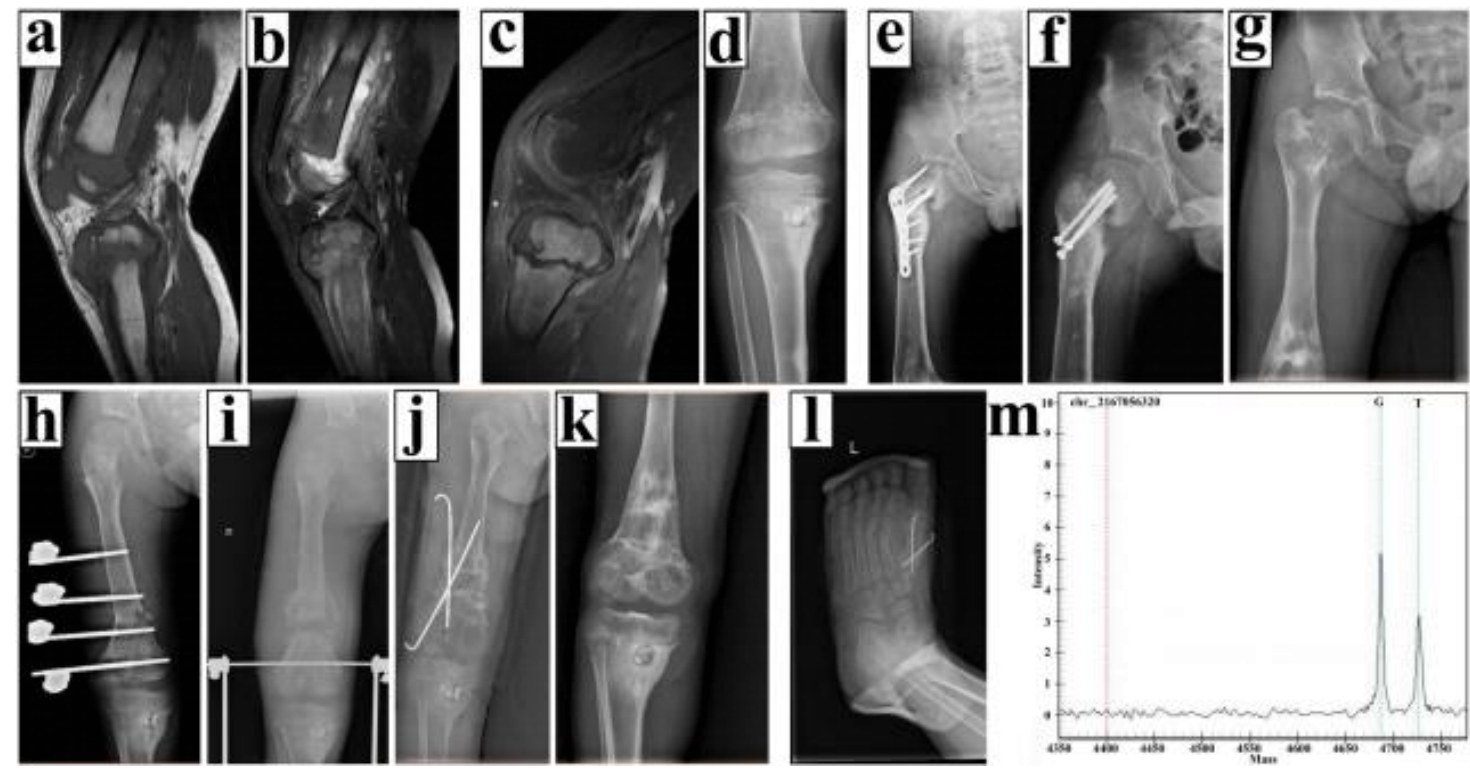

Fig 2 Auxiliary inspection results. a, b the TIWI and FST2WI MRI of the knee joint at 2 years and 11 months. $\mathbf{c}$ the FST1WI MRI of the knee joint at 5 years and 5 months. $\mathbf{d}$ X-ray images one year after surgery. $\mathbf{e}$ X-ray images of right femoral neck fracture open reduction and plate screw internal fixation 1 year after operation. $\mathbf{f}, \mathbf{g}$ X-ray image of hollow screw internal fixation for right femoral neck fracture at 1.5 months and 3 years after operation. $\mathbf{h}-\mathbf{k} \mathrm{X}$-ray images of right distal femoral fractures after surgery. I X-ray image of left metatarsal fracture after surgery. m Whole exome sequencing of children. Gene: SCN9A. Reference sequence: NM_002977.3. Nucleotide changes: c.4796 G>T. Amino acid changes: p.Arg1599Leu. Gene subregion: EX27E. Chromosome position: chr2:167056320.

\section{Discussion}

When young patients have unexplained subcutaneous congestion, tissue damage and multiple fractures, CIP should be regarded as a possible disease [2]. With the development of genetic testing technology, genetic sequencing has gradually become a reliable diagnostic method. The SCN9A gene on chromosome 2q24.3 encodes the $\alpha$ subunit of the voltage-gated sodium channel Nav1.7, which plays a key role in pain transmission [3]. We performed whole-exome sequencing on this patient and found that the heterozygous mutation c. $4796 \mathrm{G}>\mathrm{T}$ in exon $27 \mathrm{E}$ of SCN9A, and the father of the child was a carrier of the mutation at this locus. The CIP (OMIM: 243000) inheritance model is mainly autosomal recessive inheritance, homozygous or compound heterozygous 
mutations can also lead to the occurrence of this disease. We maintain that the new mutation in this gene locus may be the cause of sensory disturbance.

Loss of pain often leads to aggravation of wounds or fractures. In clinical treatment, the possible complications of invisible fractures need to be paid attention to. Generally speaking, children's fractures heal quickly, but CIP children's fractures are characterized by late discovery, difficult diagnosis, susceptibility to infection, and low coordination, and often fail to meet the requirements of anatomy or functional reduction. Therefore, bone shaft fractures require early anatomical reduction and firm fixation. Current techniques such as open reduction combined with external fixators or elastic intramedullary nails can better restore the lower limb gravity line $[4,5]$.

Open reduction and internal fixation for metaphyseal fractures may lead to implant loosening, failure of internal fixation and infection, causing nonunion and severe malunion. Surgical treatment should be avoided [6]. This patient was hospitalized with right femoral osteomyelitis at the age of 2, and imaging examination revealed an occult right tibial epiphyseal fracture (type IV). Premature weight-bearing activities after the fracture caused uneven growth of the epiphyses, which eventually made the right knee joint valgus deformity. Given the lack of pain in patients with CIP protective reflexes, patient education is particularly important in this population conservative treatment or surgical treatment.

Currently there is no effective treatment options for this disease, mostly symptomatic therapy [7]. The recurring low-energy fractures put the children under severe psychological pressure and increased the economic burden on the family and society. Zoledronic acid is a diphosphate compound that induces osteoclast apoptosis by interfering with the adhesion of osteoclasts to the bone surface, and promotes bone formation by stimulating the activity of osteoblasts $[8,9]$. Although zoledronic acid has not yet been approved by the FDA for use in children, studies have shown that the drug is safe and tolerable for short-term or long-term treatment in children [10-12]. In this case, after the child was treated with zoledronic acid, no drug-related complications occurred and no new fractures occurred during the 3 -year follow-up. This situation may be attributed to that zoledronic acid can inhibit bone resorption, promote bone formation, increase bone density, and ultimately avoid new fractures. For those CIP patients with repeated low-energy fractures without effective preventive measures, we deem it can be tried. Furthermore, CIP management needs to increase the awareness of patients and parents of the disease, and reduce the risk of injury in study or life to avoid trauma.

\section{Conclusion}

Patient with multiple fractures of the whole body caused by CIP with low energy is extremely rare. After fractures, healing is difficult and the incidence of complications is high. The patient's painless characteristics pose a huge challenge for early detection and treatment. Genetic testing technology can assist in diagnosis. Injuries should be strictly prevented in life, and if necessary, zoledronic acid can be used in combination to prevent low-energy fractures.

\section{Acknowledgements}

The authors thank the other investigators and partcipants of the study for their valuable contributions.

\section{Reference}

1. Dearborn GVN. A case of congenital pure analgesia. J Nery Ment Dis. 1932, 75: 612-615.

2. https://doi.org/10.1097/00005053-193206000-00002

3. Sathiaseelan S, Rayar U. The mystery of the broken bones. CMAJ. 2003, 169: 1189-90.

4. Cox JJ, Reimann F, Nicholas AK, et al. An SCN9A channelopathy causes congenital inability to experience pain. Nature. 2006, 444(7121): 894-8.

5. https://doi.org/10.1038/nature05413

6. Rollo G, Guida P, Bisaccia M, et al. TEN versus external fixator in the management of pediatric diaphyseal femora fractures: evaluation of the outcome. Eur J Orthop Surg Traumatol. 2018, 28: 1421-1428.

7. https://doi.org/10.1007/s00590-018-2201-3

8. Bisaccia M, Meccariello L, Manni M, et al. Treatment of acute proximal humeral fractures in children with modular external fixator. J Acute Dis. 2016, 5: 497-501. https://doi.org/10.1016/j.joad.2016.08.021

9. Hartono F, Tanjung C, E Besinga K, et al. Catastrophic results due to unrecognizing of congenital insensitivity to pain with anhidrosis in children with multiple long bones fractures: A case report of 27 years follow-up of two siblings. Int J Surg Case Rep. 2020, 73:213-217. https://doi.org/10.1016/j.ijscr.2020.07.010

10. Schwartzlow C, Kazamel M. Hereditary sensory and autonomic neuropathies: adding more to the classification. Curr Neurol Neurosci Rep. 2019, 19: 52. https://doi.org/10.1007/s11910-019-0974-3

11. Dunford JE, Thompson K. Coxon FP, et al. Structure-activity relationships for inhibition of farnesyl diphosphate synthase in vitro and inhibition of bone resorption in vivo by nitrogen-containing bisphosphonates. J Pharmacol Exp Ther. 2001, 96: 235-242.

12. Mäkitie O. Causes, mechanisms and management of paediatric osteoporosis. Nat Rev Rheumatol. 2013, 9(8): 465-75.

13. https://doi.org/10.1038/nrrheum.2013.45

14. Brown JJ, Zacharin MR. Safety and efficacy of intravenous zoledronic acid in paediatric osteoporosis. J Pediatr Endocrinol Metab. 2009, 22(1): 55-63. https://doi.org/10.1515/jpem.2009.22.1.55

15. Al-Agha AE, Shaikhain TA, Ashour AA. Safety \& Efficacy of Cyclic Zoledronic Acid Therapy on Pediatric Secondary Osteoporosis. Glob J Health Sci. 2016, 8(8): 48648.

16. https://doi.org/10.5539/gjhs.v8n8p20

17. Otaify GA, Aglan MS, Ibrahim MM, et al. Zoledronic acid in children with osteogenesis imperfecta and Bruck syndrome: a 2-year prospective observational study. Osteoporos Int. 2016 , 27(1): 81-92.

18. https://doi.org/10.1007/s00198-015-3216-9 